Beyond Expulsion 
Stanford Studies in Jewish History and Gulture edited by Aron Rodrigue and Steven J. Zipperstein 


\title{
Beyond Expulsion
}

\author{
Jews, Christians, and \\ Reformation Strasbourg
}

Debra Kaplan

STANFORD UNIVERSITY PRESS STANFORD, CALIFORNIA 
Stanford University Press

Stanford, California

(C) 20 II by Debra Kaplan.

All rights reserved.

No part of this book may be reproduced or transmitted in any form or by any means, electronic or mechanical, including photocopying and recording, or in any information storage or retrieval system without the prior written permission of Stanford University Press.

Printed in the United States of America on acid-free, archival-quality paper

Library of Congress Cataloging-in-Publication Data

Kaplan, Debra.

Beyond expulsion : Jews, Christians, and Reformation Strasbourg / Debra Kaplan. p. $\mathrm{cm}$.

Includes bibliographical references and index.

ISBN 978-0-8047-7442-O (cloth : alk. paper)

I. Jews-France-Strasbourg-History-I6th century. 2. Jews-France-

Strasbourg-History-I7th century. 3. Strasbourg (France) -Ethnic relationsHistory-I6th century. 4. Strasbourg (France)-Ethnic relations-History-17th century. 5. Strasbourg (France)-Church history-I6th century. 6. Strasbourg (France) - Church history-I7th century. 7. Judaism-Relations-Christianity.

8. Christianity and other religions-Judaism. 9. Reformation-France-Strasbourg.

I. Title.

DSI35.F85S $775201 \mathrm{II}$

305.892'404439540903I-dc22

2010035570

Typeset by Bruce Lundquist in I0.5/14 Galliard 
יהושע העשל Szyje Heschel Kofman

גיטל Gitel Feith Kofman אליהו Elias Kofman מינדל Mina Kofman שם עולם אתן לו אשר לא יכרת מינלת 
